\title{
Gynaecological Cancers in HIV Positive and Negative Women-A Single-Center Retrospective Study (2008-2017)
}

\author{
Ijeoma Victoria Ezeome1,2*, Theophilus Ogochukwu Nwankwo',2, Uchenna Anthony Umeh",2, \\ Leonard Ogbonna Ajah1,2
}

${ }^{1}$ Department of Obstetrics and Gynaecology, Faculty of Medical Sciences, College of Medicine, University of Nigeria, Ituku-Ozalla Campus, Enugu, Nigeria

${ }^{2}$ Department of Obstetrics and Gynaecology, University of Nigeria Teaching Hospital, Ituku-Ozalla Enugu, Nigeria

Email: *ezeomeij@gmail.com, ^ijeoma.ezeome@unn.edu.ng

How to cite this paper: Ezeome, I.V., Nwankwo, T.O., Umeh, U.A. and Ajah, L.O. (2022) Gynaecological Cancers in HIV Positive and Negative Women-A Single-Center Retrospective Study (2008-2017). Open Journal of Obstetrics and Gynecology, 12, 124139.

https://doi.org/10.4236/ojog.2022.122013

Received: December 27, 2021

Accepted: February 14, 2022

Published: February 17, 2022

Copyright $\odot 2022$ by author(s) and Scientific Research Publishing Inc. This work is licensed under the Creative Commons Attribution International License (CC BY 4.0).

http://creativecommons.org/licenses/by/4.0/ (c) (i) Open Access

\begin{abstract}
Background/Objective: The association between Human Immunodeficiency Virus (HIV) and invasive cervical carcinoma is fully recognized. However, the effect of HIV and antiretroviral therapy on the morbidity and mortality of other gynaecological cancers have not been conclusively determined. Our study objective was to examine the effects of HIV on patient age at presentation, prevalence, and severity of the illness of various gynaecological cancers diagnosed in University of Nigeria Teaching Hospital (UNTH), Enugu over the period 2008-2017. Methods: This was a retrospective cross-sectional study of 224 patients who were managed in UNTH for different gynaecological malignancies. Ethical clearance was obtained from the Research Ethics Committee of the UNTH, Enugu. Data analysis was done with SPSS software with results expressed in descriptive statistics of simple frequency and percentage, and p-value set at $<0.05$. Results: A total of 224 patients were studied. Twenty-five percent of HIV positive patients were aged $31-40$ years at presentation compared to $12 \%$ of HIV negative patients. The commonest gynaecological cancer was cervical cancer with a higher proportion among the HIV-positive patients. While $32 \%$ of HIV negative patients presented at FIGO stages $1-2$ Versus $8.3 \%$ of HIV positive patients, $58.3 \%$ and $33.3 \%$ of HIV positive patients presented at stages 3 and 4 respectively. Only $8.3 \%$ of HIV positive patients presented with ovarian cancer compared with $31 \%$ of HIV negative patients. A higher proportion of HIV positive patients presented with vulvar cancer (16.7\%), but no endometrial or choriocarcinoma/GTD, compared with HIV negative patients. Conclusion: HIV positive clients present at an earlier age with more advanced disease, mostly cervical cancer of the squamous cell variety, with minimal non-AIDS defining cancers over the study
\end{abstract}


period in UNTH, Enugu.

\section{Keywords}

Invasive Cervical Cancer, Non-AIDS Defining Cancers, Severity of Illness, Combination Anti-Retroviral Therapy

\section{Introduction}

Gynaecological malignancies are a major public health problem. Approximately, 1 out of 6 and 1 in 4 cancer cases among women worldwide and in developing countries are a gynaecological cancer respectively [1]. It accounted for $25 \%$ of all new cancers diagnosed in women aged up to 65 years compared with $16 \%$ in the developed world according to a global report shown by the International Agency for Research on Cancer [2]. While endometrial cancer is commonest in developed countries, cervical cancer is commonest in developing countries including Nigeria, where it is the leading cause of death among women aged 35 to 45 years [3].

The increased incidence and mortality from cervical cancer in developing nations have been attributed to ignorance, poverty and the absence of an organised screening program as obtainable in most developed nations [4] [5]. Epidemiologically, HIV, human papillomavirus (HPV), and cervical cancer are associated, and invasive cervical carcinoma is one of the Autoimmune Deficiency Syndrome (AIDS)-defining malignancies [6]. Women living with HIV present a 5.4-fold higher risk of developing cervical cancer than HIV-negative women [7]. Though there is significant body of literature on cervical cancer in HIV positive women, little is known about other gynecologic cancers in this population [8].

The HAART regimen for the treatment of HIV has led to a marked reduction in disease progression among people living with HIV and AIDS (PLWHA), thereby markedly improving survival [9]. This has exposed HIV positive persons to age related diseases including NADCs with a concomitant decline in the incidence of AIDS defining malignancies such as Kaposi Sarcoma, non-Hodgkin Lymphoma and invasive cervical cancer. However, it is known that HAART does not fully restore health and infected patients remain at increased risk of a number of non-AIDS complications, including cardiovascular disease, liver disease, kidney disease, bone disease, and neurocognitive decline [10]. It is important to note that the incidence of NADMs amongst PLWHA does not appear to be due to age alone, as PLWHA have an increased risk of malignancy compared to age-matched cohorts in the general population, even after controlling for behavioural differences [11]. The HIV positive populations have also been found to be at greater risk of viral co-infection (such as HPV, HBV and EBV) and tumours associated with these viral oncogenic viruses, as well as those with no viral aetiology [12]. Studies of lung, liver, anal and colorectal cancers have shown that there is not only an overall increased risk of NADC diagnosis among HIV 
infected individuals, but also an earlier age at cancer presentation [13].

Sub-Saharan Africa carries a disproportionate burden of HIV, accounting for more than $70 \%$ of the global burden of infection [14]. Nigeria is estimated to have the second highest burden of HIV/AIDS worldwide with its $>160$ million population (2011 World bank estimate) and HIV prevalence rate of $3.4 \%$ among ages 15 - 49 in 2011, giving an estimated 3.2 million people living with HIV in 2011 [15].

HIV prevalence varies among different geographic regions with different socio-cultural practices, being low in Muslim communities with strict practices, as well as variation across different states in Nigeria [16]. The high prevalence of HIV may be related to poverty, early marriage, early age at sexual debut, living in an urban area, and multiparity.

Worldwide, women account for more than half the number of people living with HIV [8]. According to the National Agency for the Control of AIDS [17], with the Nigeria national HIV prevalence rate (2019) at $1.4 \%$ among adults aged 15 - 49, women are twice as likely to be living with HIV. It is therefore important to study the effects of HIV infection on the incidence and prognosis of gynaecological cancers, the outcome of which may guide the implementation of a comprehensive organised program of care for WLWHA (Women Living with HIV and AIDS) in Nigeria.

While several studies [2] [18] [19] [20] [21] have been carried out to determine the pattern of presentation, age distribution and disease severity of gynaecological cancers in the general population, there is a dearth of data among HIV positive patients in this environment.

\section{Aims}

The study objectives were therefore to examine the effects of HIV prevalence on patient age at presentation, prevalence, and severity of illness of various gynaecological cancers, as well as the prevalence of NADC among the HIV positive population, compared to the HIV negative population in University of Nigeria Teaching Hospital Enugu over the period 2008 to 2017.

\section{Methods}

We conducted a retrospective study of all adult female patients 18 years and above diagnosed with gynaecological cancers from January 2008 to December 2017 at University of Nigeria Teaching Hospital, Enugu Nigeria.

After Human Research Ethics Committee (HREC) approval was obtained from the hospital, with the aid of a study proforma, data was collected from patient gynae-oncology case notes, HIV clinic records for those that were retroviral positive, theatre and gynaecological ward records for those that had operative interventions or were admitted into the wards. Data extraction was between June 2018 and February 2019.

Extracted data include age at presentation, retroviral status, type of cancer (s) 
diagnosed, risk factors, stage of illness at presentation, treatment given, histologic diagnosis, and status of patient during the study. Data on viral load and CD4 count were poorly recorded or unavailable, hence not part of data collected.

Data analysis was done using the Statistical Package for Social Sciences Software (SPSS) version 20 (Chicago, IL, USA) with results expressed in descriptive statistics of simple frequency and percentage. The Pearson Chi-square test was used to compare age range at presentation, age at first coitus, clinical diagnosis, stage of illness and status at study period between HIV positive and negative patients, with level of significance set at $\mathrm{P}<0.05$.

\section{Results}

Out of 250 case notes available over the study period, 224 had adequate data for inclusion into the study giving an $89.6 \%$ data retrieval rate.

\subsection{Demographic Characteristics}

As shown in Table 1, the commonest age at presentation among the 224 studied women was 51 - 60 years (32.1\%). Majority were married (71.4\%), multiparous (66\%), Christians (98.2\%), self-employed (59.8\%) and had at least secondary education (59.8\%). Twenty-four (10.7\%) were HIV positive.

\subsection{Factors Associated with Gynaecological Cancers}

As depicted in Table 2, among the 224 studied women, 22 (9.8\%) and 108 women $(48.2 \%)$ had coitarche at less than 10 years and $10-13$ years respectively giving a total of $58 \%$. Only $10.7 \%$ had their sexual debut at $18-21$ years of age. One hundred and eight-eight women (83.9\%) had no knowledge of Pap smear, and only twelve (5.4\%) had a pap smear done within 3 years prior to their presentation. Most of the patients (73.2\%) gave history of no multiple sexual partners.

\subsection{Presenting Symptoms\#}

The most common symptoms at presentation were intermenstrual bleeding (57.1\%), Abdominal swelling (50.9\%), postmenopausal bleeding (25\%), and Postcoital bleeding (18.4\%). Other symptoms include abdominal pain (13.4\%), vaginal discharge (8\%), Weight loss (4.5\%), vulval swelling (4.5\%) and leg swelling (4.5\%). Less common symptoms include vulval mass, vulvar pain, incomplete urinary emptying, and generalized body pains. There was no significant difference in symptomatology between the HIV positive and HIV negative patients.

\# Patients presented with multiple symptoms.

\subsection{Clinical Diagnosis and International Federation Gynaecology and Obstetrics (FIG0) Staging of Illness at Presentation}

As depicted in Table 3, most patients presented at stage 4 (40.2\%) followed by 
stage $3(30.3 \%)$. The least number of patients presented at stage $1(11.6 \%)$. The more common clinical diagnoses of the patients were Cervical cancer (50\%) and Ovarian cancer $(28.5 \%)$. Only $10.7 \%, 6.3 \%$ and $4.5 \%$ of the studied patients had a diagnosis of uterine, vulva and Choriocarcinoma/GTD.

Table 1. Demographic characteristics.

\begin{tabular}{|c|c|c|}
\hline Variable & Frequency (224) & Percentage (100\%) \\
\hline \multicolumn{3}{|l|}{ Age (in years) } \\
\hline $21-30$ & 16 & 7.1 \\
\hline $31-40$ & 30 & 13.4 \\
\hline $41-50$ & 50 & 22.3 \\
\hline $51-60$ & 72 & 32.1 \\
\hline $61-70$ & 46 & 20.5 \\
\hline$>70$ & 10 & 4.5 \\
\hline \multicolumn{3}{|l|}{ Marital Status } \\
\hline Single & 30 & 13.4 \\
\hline Married & 160 & 71.4 \\
\hline Separated & 8 & 3.6 \\
\hline Divorced & 8 & 3.6 \\
\hline Widowed & 18 & 8.0 \\
\hline \multicolumn{3}{|l|}{ Parity } \\
\hline 0 & 38 & 17.0 \\
\hline $1-4$ & 148 & 66.0 \\
\hline or $>5$ & 38 & 17.0 \\
\hline \multicolumn{3}{|l|}{ Religion } \\
\hline Christianity & 220 & 98.2 \\
\hline Islam & 2 & 0.9 \\
\hline Traditional & 2 & 0.9 \\
\hline \multicolumn{3}{|l|}{ Educational status } \\
\hline Non-formal & 28 & 12.5 \\
\hline Primary & 62 & 27.7 \\
\hline Secondary & 82 & 36.6 \\
\hline Tertiary & 52 & 23.2 \\
\hline \multicolumn{3}{|l|}{ Employment status } \\
\hline Unemployed & 46 & 20.5 \\
\hline Self-employed & 134 & 59.8 \\
\hline Private/Govt employ & 44 & 19.7 \\
\hline \multicolumn{3}{|l|}{ HIV status } \\
\hline HIV positive & 24 & 10.7 \\
\hline HIV negative & 200 & 89.3 \\
\hline
\end{tabular}


Table 2. Factors associated with gynaecological cancers.

\begin{tabular}{ccc}
\hline Variable & Frequency (224) & Percentage (100\%) \\
\hline $\begin{array}{c}\text { Age at first intercourse } \\
\text { (years) }\end{array}$ & 22 & 9.8 \\
$<10$ & 108 & 48.2 \\
$10-13$ & 64 & 28.6 \\
$14-17$ & 24 & 10.7 \\
$18-21$ & 4 & 1.8 \\
$>22$ & 2 & 0.9 \\
Not indicated & & 26.8 \\
Multiple sexual partners & 60 & 73.2 \\
Yes & 164 & 16.1 \\
No & & 83.9 \\
Yes & 36 & 5.4 \\
No & 188 & 94.6 \\
\hline Knowledge of Pap smear & & \\
No & 212 & \\
Had Pap smear within 3 & & \\
years prior to presentation & & \\
\hline Yes & & \\
\hline
\end{tabular}

Table 3. Diagnosis and FIGO stage of Illness.

\begin{tabular}{ccc}
\hline Variable & Frequency $(224)$ & Percentage $(100 \%)$ \\
\hline FIGO Stage of illness & 26 & 11.6 \\
1 & 40 & 17.9 \\
2 & 68 & 30.3 \\
3 & 90 & 40.2 \\
4 & & \\
Clinical Diagnosis & 112 & 50.0 \\
Cervical cancer & 64 & 28.5 \\
Ovarian cancer & 24 & 10.7 \\
Uterine cancer & 14 & 6.3 \\
Vulva cancer & 10 & 4.5 \\
Choriocarcinoma/GTD & &
\end{tabular}

\subsection{Treatment and Outcome of Illness}

As depicted in Figure 1, ten patients (4.5\%) were discharged against medical advice (AMA) due to lack of funds and ignorance of the disease, while twelve patients $(5.4 \%)$ had examination under anaesthesia (EUA), staging and biopsy after which they were lost to follow-up. Sixty-nine patients $(30.4 \%)$ had sequential chemoradiation (chemotherapeutic agents-paclitaxel and carboplatin), sixty-two patients $(27.7 \%)$ had debulking surgery and chemotherapy, and thirty-six 


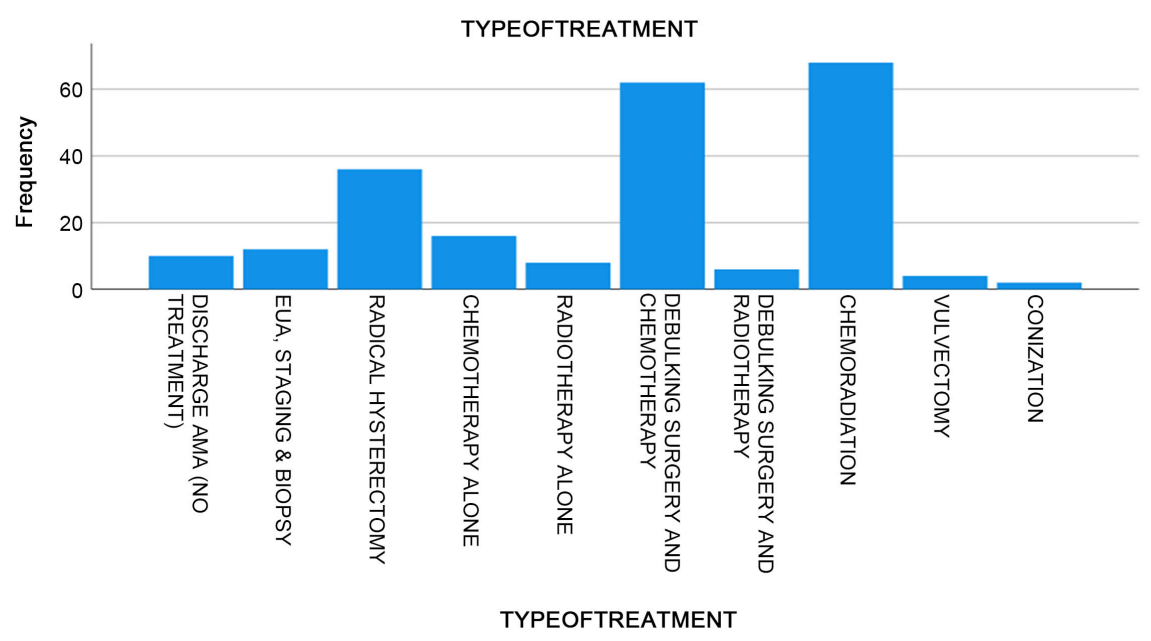

Figure 1. Treatment.

(16.1\%) had radical hysterectomy. Other forms of treatment included debulking surgery and radiotherapy for 6 patients (2.7\%), chemotherapy alone for 16 patients $(7.1 \%)$, radiotherapy alone for 8 patients (3.6\%), vulvectomy for 4 patients (1.8\%) and conization for 2 patients $(0.9 \%)$. Cervical cancer was treated with radical hysterectomy and lymphadenectomy for stages $1-2 \mathrm{~A}$. Stages $2 \mathrm{~B}$ and above had adjuvant chemotherapy ( 3 to 4 courses of carboplatin \& paclitaxel) and for those downgraded to $2 \mathrm{~A}$ was further treated with radical hysterectomy, and/or followed by radiotherapy. Ovarian cancer, uterine cancer, gestational trophoblastic disease/choriocarcinoma and vulval cancers were treated according to National Comprehensive Cancer Network (NCCN) Clinical Practice Guidelines in Oncology. However, completion of the courses of treatment was dependent on patients' financial status and understanding of the course of the illness.

All the HIV positive patients were on HAART (Tenofovir, lamivudine and dolutegravir) for varied periods ranging from 1 to 6 years. The CD4 counts and viral load were not found in the case records, hence not part of the data analysis.

\subsection{Comparison between Age Range at Presentation, Age at First Intercourse, Clinical Diagnosis, Stage of Illness and Status at Time of Study between HIV Positive and HIV Negative Women}

As depicted in Table 4, twenty-five percent and $41.7 \%$ of the HIV positive clients presented at 31 - 40 and 41 - 50 years of age compared to $12 \%$ and $20 \%$ of HIV negative women respectively. The proportion of HIV positive and negative patients aged $51-60$ years were similar, but there was no HIV positive patient presenting in the second, sixth and seventh decades of life.

There is also a significantly higher frequency of early coitarche among HIV positive patients with, six (25\%) and fourteen (58.3\%) at ages less than 10 years, and 10 - 13 years compared to sixteen (8\%) and ninety-four (47\%) for the same age groups in HIV negative women. 
Table 4. Comparison between Age range at presentation, Age at first intercourse, Clinical diagnosis, Histological diagnosis, Stage of illness, and status at time of study between HIV positive and HIV negative women.

\begin{tabular}{|c|c|c|c|}
\hline Variable & HIV +ve women (24) & HIV -ve women (200) & Pearson chi-square test \\
\hline \multicolumn{4}{|l|}{ Age range } \\
\hline $21-30$ & 0 & $16(8 \%)$ & \multirow{6}{*}{$\star 0.007$} \\
\hline $31-40$ & $6(25 \%)$ & $24(12 \%)$ & \\
\hline $41-50$ & $10(41.7 \%)$ & $40(20 \%)$ & \\
\hline $51-60$ & $8(33.3 \%)$ & $64(32 \%)$ & \\
\hline $61-70$ & 0 & $46(23 \%)$ & \\
\hline$>70$ & 0 & $10(5 \%)$ & \\
\hline \multicolumn{4}{|l|}{ Age at $1^{\text {st }}$ coitus } \\
\hline$<10$ & $6(25 \%)$ & $16(8 \%)$ & \multirow{6}{*}{$\star 0.037$} \\
\hline $10-13$ & $14(58.3 \%)$ & $94(47 \%)$ & \\
\hline $14-17$ & $4(16.7 \%)$ & $60(30 \%)$ & \\
\hline $18-21$ & 0 & $24(12 \%)$ & \\
\hline$\geq 22$ & 0 & $4(2 \%)$ & \\
\hline Unindicated & 0 & $2(1 \%)$ & \\
\hline \multicolumn{4}{|l|}{ Clinical Diagnosis } \\
\hline Cervical cancer & $18(75 \%)$ & $94(47 \%)$ & \multirow{5}{*}{${ }^{\star} 0.003$} \\
\hline Ovarian cancer & $2(8.3 \%)$ & $62(31 \%)$ & \\
\hline Uterine Cancer & 0 & $24(12 \%)$ & \\
\hline Choriocarcinoma/GTD & 0 & $10(5 \%)$ & \\
\hline Vulva cancer & $4(16.7 \%)$ & $10(5 \%)$ & \\
\hline \multicolumn{4}{|l|}{ Histopathology of specimen } \\
\hline \multicolumn{4}{|l|}{ Cervix } \\
\hline No histology (Discharged AMA-No treatment) & 0 & $10(5 \%)$ & \\
\hline Adenocarcinoma & 0 & $12(6 \%)$ & \\
\hline Adeno-squamous $\mathrm{Ca}$ & 0 & $4(2 \%)$ & \\
\hline Well diff. invasive SCC & $18(75 \%)$ & $66(33 \%)$ & \\
\hline Undifferentiated SCC & 0 & $2(1 \%)$ & \\
\hline \multicolumn{4}{|l|}{ Ovary } \\
\hline Serous cyst-adenoCa & $2(8.3 \%)$ & $34(17 \%)$ & \\
\hline Mucinous cystadenoCa & 0 & $8(4 \%)$ & \\
\hline Endometriod $\mathrm{Ca}$ & 0 & $3(1.5 \%)$ & \\
\hline Granulosa cell Tumour & 0 & $8(4 \%)$ & \\
\hline Dysgerminoma & 0 & $2(1 \%)$ & \\
\hline Mixed Mullerian Tumour & 0 & $2(1 \%)$ & \\
\hline Sertoli-Leydig cell Tumou & 0 & $2(1 \%)$ & \\
\hline Immature teratoma & 0 & $2(1 \%)$ & \\
\hline Serous Papillary Ca & 0 & $1(0.5 \%)$ & \\
\hline \multicolumn{4}{|l|}{ Uterus } \\
\hline Endometriod adenocarcinoma & 0 & $22(11 \%)$ & \\
\hline Uterine rhabdomyosarcoma & 0 & $2(1 \%)$ & \\
\hline Chorio-Carcinoma/GTD & 0 & $10(5 \%)$ & \\
\hline \multicolumn{4}{|l|}{ Vulva } \\
\hline Invasive Sq. cell Ca & $2(8.3 \%)$ & $10(5 \%)$ & \\
\hline Verrucous carcinoma & $2(8.3 \%)$ & 0 & \\
\hline
\end{tabular}




\section{Continued}

FIGO Stage of Illness

0

$26(13 \%)$

2 2(8.3\%)

$3 \quad 14(58.3 \%)$

$38(19 \%)$

$8(33.3 \%)$

$54(27 \%)$

${ }^{\star} 0.008$

$82(41 \%)$

Status at study period (06/18-02/19)

Alive

$4(16.7 \%)$

0

Alive with recurrence

Terminally ill

Lost to follow-up

Dead
The HIV positive patients more frequently had a clinical diagnosis of cervical cancer (75\%) compared to HIV negative patients (47\%). Only $8.3 \%$ of HIV positive patients had ovarian cancer compared to $31 \%$ of HIV negative patients. There was also no uterine cancer or choriocarcinoma among HIV positive patients compared to $12 \%$ and $5 \%$ respectively among HIV negative patients in this series. A higher proportion (16.7\%) of HIV positive patients were noted to have vulva cancer compared to HIV negative women (5\%).

The HIV positive patients tended to present more commonly in stage 3 (58.3\%) compared to $27 \%$ for HIV negative patients. Stage 4 disease comprised of $33.3 \%$ of HIV positive as against $41 \%$ of HIV negative patients. Only $8.3 \%$ of HIV positive patients presented with stage 2 disease as against $19 \%$ of HIV negative patients, with no HIV positive patient presenting in stage 1 compared with $13 \%$ of HIV negative patients.

The commonest histology among HIV positive patients was invasive squamous cell cancer (ISCC) of cervix (75\%). Others were ISCC of vulva $(8.3 \%)$, verrucous cancer of vulva (8.3\%), and serous cystadenocarcinoma of the ovary (8.3\%).

A much lower proportion of HIV positive patients (16.7\%) compared with $26 \%$ of HIV negative patients were alive during the study period. Though only two $(8.3 \%)$ HIV positive patients compared with fifty-two (26\%) HIV negative patients were confirmed dead over the period of the study, a higher proportion of the HIV positive patients (75\%) were lost to follow-up compared with HIV negative patients $(38 \%)$.

\section{Discussion}

The prevalence of HIV was $10.7 \%$ in the studied patients, which is approximately 7.5 times higher than in the general population [17], 5 times higher than a study among surgical oncology patients in Guinea [22], but agrees with the $10.3 \%$ obtained in a similar study in Zaria, Nigeria [23]. However, it is much lower than the $21.8 \%$ obtained in a South African study [24]. 
The modal age-range at presentation of the gynaecological cancer patients during the study period was $51-60$ years, which is much higher than the $41-50$ years obtained in Zaria [23] and Orlu [19], but similar to that obtained in Abakaliki [20] and the same institution [18] a decade ago. It however remains lower than what obtains in developed countries where the commonest age at presentation is between the $6^{\text {th }}$ and $7^{\text {th }}$ decades of life [25]. This may be related to higher socioeconomic status, with availability and accessibility of organised screening programs for gynaecological cancers. More than two thirds of the HIV positive patients were however aged 30 - 50 years compared to one-third of the HIV negative population. This agrees with the findings by Moodley et al. in a South African study [26] where the mean age of HIV-positive patients was 15 years younger than that of the HIV-negative patients. Patients with HIV and AIDS defining Cancers tend to be younger, probably due to a younger HIV population [27].

Majority of the patients had early coitarche with a higher frequency among HIV positive patients, but history of multiple sexual partners was low. In Nigeria as occurs in most African countries, early marriage with associated polygamous unions is common and this increases the risk of infection-related cancers especially among HIV positive persons [28].

Most of our patients presented with cervical cancer, which is the second most common female cancer after breast cancer in Nigeria, with an age standardized rate of 34.5 cases per 100,000 women in 2010 [29]. Our finding is in agreement with previous studies in Enugu [18], Abakaliki [20], and Ghana [30]. However, there was a higher proportion of cervical cancer among the HIV positive patients, which is in agreement with the findings of Adewuyi et al. [23] in Nigeria and other regions of the world [31]. Cervical cancer is the third leading cause of death among women in low-income countries [32], which are often regions with the greatest burden of HIV [33].

Ovarian cancer was the second commonest cancer in our series, similar to the findings in previous studies in Enugu [18] and Zaria [23]. However, only 8.3\% of HIV positive patients had serous cystadenocarcinoma of the ovary and no endometrial cancer compared to $31 \%$ and $11 \%$ respectively in the HIV negative patients. This is no surprise as the first documented report of ovarian cancer in a HIV positive patient was in 1992 [34], but differs from the systematic review by Smith et al. [8] where the incidence of ovarian and vulvovaginal cancers was higher than the general population, while incidence of endometrial cancer was similar.

Our finding of $16.7 \%$ of vulvar cancers among the HIV positive patients confirms that in population with a high prevalence of HIV, there is a high incidence of vulvar cancer [23] [35]. This could be due to the fact that vulva cancer is mostly associated with Human papillomavirus, which is also implicated in cervical cancer. Vulvar cancer in young human immunodeficiency virus-seropositive women may be associated with other human papillomavirus-related diseases and immunosuppression, as evidenced by low CD4 counts and the presence of antecedent acquired immune deficiency syndrome-defining illnesses [36]. Due to poor records, we had no data on CD4 counts. 
The commonest histologic diagnosis was well differentiated invasive squamous cell carcinoma of the cervix, similar to findings in other studies [21] [23] [37]. There was no uterine cancer among the HIV positive patients, probably partly due to the fact that majority of our HIV positive patients presented at an age range of $31-50$ years which is much lower than the 60-year average age at presentation of uterine cancer in our population [38].

Majority of our patients did not have any knowledge of cervical screening with only 5.4\% of them having Papanicolaou test within 3 years of the diagnosis of gynaecologic cancer. This result confirms previous reports of low screening coverage among HIV-infected women, ranging from $9 \%$ in Tanzania [39], 10\% in Nigeria [40], to $13 \%$ in South Africa [41]. As in most low-income countries, there are no national screening or prevention programmes for cervical cancer in Nigeria, and awareness of cervical cancer among women remain limited. The lack of regular organized cervical screening in our environment [42], especially among HIV positive patients who are at heightened risk of cervical cancer may be one of the reasons for the increased prevalence of cervical cancer among our HIV-infected patients.

As the primary prevention of cervical cancer by HPV vaccination is not effective in women already infected by HPV, secondary prevention through early detection and treatment of precancerous lesions of the cervix is crucial. It has been suggested that rapid point of care HPV test in self-obtained vaginal samples permitting both first-line screening, as well as triaging of HPV positive women with either visual inspection of the cervix after acetic acid application (VIA), visual inspection after application of Lugol's iodine (VILI), or cytology, followed by treatment may best serve women in low resource settings [43].

Most of the gynaecological cancer patients presented at an advanced stage of the disease. This is consistent with other studies [44] [45] where late presentation, with advanced and metastatic disease is the norm. This is related to poverty, ignorance, and African sociocultural norms of secrecy associated with gynaecological issues [46]. The HIV positive patients presented with more severe disease compared with HIV negative patients. This agrees with the findings by Maiman et al. [47], but differs from findings by Levinson et al. [31] where greater than half of the patients presented with early-stage disease.

Though all the HIV positive patients had HAART between $1-6$ years prior to presentation with gynaecological cancer, start of treatment most likely was during the chronic phase of the infection which may have affected their response to the antiretroviral drugs in combating disease progression and incidence of AIDSdefining cancers. Early combination antiretroviral therapy (cART) has been shown to reduce cancer mortality in HIV-infected patients with Kaposi Sarcoma (KS) and Non-Hodgkin Lymphoma [11]. Response to cART have been found to be most beneficial during the acute phase of the infection and within 10 months of infection compared to the chronic phase of the infection [48]. Due to the retrospective nature of our study, we could not determine the time interval between HIV infection and presentation of our patients, but judging from our en- 
vironment where there is no organized screening, most of our clients are diagnosed when they report with symptoms of immunodeficiency during which the window of opportunity for maximal response to the cART is already lost. The increased mortality among our HIV positive population may be related to disease stage, and late start off of HAART.

Majority of the patients had standard cancer treatment relevant to the type and stage of cancer, bearing the mind the performance status of the patients. This is the opinion of four-fifth of US gynaecologists [49] and guidelines by the National Comprehensive Cancer Network (NCCN) [50].

Though a higher proportion of the HIV negative patients were confirmed dead in our series, a higher proportion of the HIV positive patients were lost to follow-up. With a higher proportion of them presenting with more advanced disease, it is probable that they were dead. The HIV infected cancer patients were more likely to die than HIV negative ones [51].

\section{Conclusion}

HIV positive patients present at an earlier age with more advanced disease mostly invasive cervical cancer of the squamous variety. Even though overall survival of HIV-infected patients has improved with HAART worldwide, early onset of treatment is essential to maintain adequate levels of immune competence among patients treated in University of Nigeria Teaching Hospital. This will reduce the onset and progression of the AIDS Defining Malignancies (ADM), including reduction in HIV specific morbidity and mortality. There should also be a concerted program of routine regular cervical screening as part of routine management for all HIV positive women.

\section{Limitations}

The following limitations to the study are acknowledged. This is a retrospective study hence some of the case records were unavailable. It is possible some women were not identified for inclusion. Data on CD4 count, viral load, interval between HIV diagnosis and HAART intake, as well as co-morbidities were unavailable.

\section{Authorship Statement}

All authors contributed sufficiently to be listed as authors and take responsibility for the work

A

1) Conception and design: Ezeome Ijeoma, Umeh Uchenna;

2) Acquisition of data: Umeh Uchenna, Nwankwo Theophilus;

3) Analysis and interpretation of data: Ezeome Ijeoma, Nwankwo Theophilus, Umeh Uchenna, Ajah Leonard.

B.

1) Drafting the article: Ezeome Ijeoma; 
2) Revising it critically for important intellectual content: Ezeome Ijeoma, Nwankwo Theophilus, Umeh Uchenna, Ajah Leonard.

C.

1) Final approval of the version to be published: Ezeome Ijeoma, Nwankwo Theophilus, Umeh Uchenna, Ajah Leonard.

\section{Conflicts of Interest}

The authors declare no conflicts of interest regarding the publication of this paper.

\section{References}

[1] Iyoke, C.A. and Ugwu, G.O. (2013) Burden of Gynaecological Cancers in Developing Countries. World Journal of Obstetrics and Gynecology, 2, 1-7.

https://doi.org/10.5317/wjog.v2.i1.1

[2] Abdullahi, H.I. and Ayogu, M.E. (2020) Pattern and Relative Frequencies of Gynecological Malignancies at the University of Abuja Teaching Hospital, Abuja. Tropical Journal of Obstetrics and Gynaecology, 37, 177-181. https://doi.org/10.4103/TJOG.TJOG 9919

[3] Adewole, I.F., Benedet, J.L., Grain, B.J. and Follen, M. (2006) Evolving a Strategic Approach to Cervical Cancer Control in Africa. Gynecologic Oncology, 99, S209S212. https://doi.org/10.1016/j.ygyno.2005.07.086

[4] Iyoke, C.A., Ugwu, G., Ezugwu, E.C., Ezeugwu, F.O., Lawal, O.L. and Onyebuchi, A.Z. (2014) Challenges Associated with the Management of Gynaecological Cancers in a Tertiary Hospital in South-East Nigeria. International Journal of Women's Health, 6, 123-130. https://doi.org/10.2147/IJWH.S55797

[5] Weiderpass, E. and Labrèche, F. (2012) Malignant Tumours of the Female Reproductive System. Safety and Health at Work, 3, 166-180.

https://doi.org/10.5491/SHAW.2012.3.3.166

[6] Bedimo, R.J., McGinnis, K.A., Dunlap, M., Rodriguez-Barradas, M.C. and Justice, A.C. (2009) Incidence of Non-AIDS-Defining Malignancies in HIV-Infected vs. Non-Infected Patients in the HAART Era: Impact of Immunosuppression. Journal of Acquired Immune Deficiency Syndromes, 52, 203-208. https://doi.org/10.1097/QAI.0b013e3181b033ab

[7] Belglaiaa, E., Souho, T., Badaoui, L., Segondy, M., Pretet, J., Guenat, D. and Mougin, C. (2018) Awareness of Cervical Cancer among Women Attending an HIV Treatment Centre: A Cross-Sectional Study from Morocco. BMJ Open, 8, Article ID: e020343. https://doi.org/10.1136/bmjopen-2017-020343

[8] Smith, A.J.B., Varma, S., Rositch, A.F. and Levinson, K. (2019) Gynecologic Cancer in HIV Positive Women: A Systematic Review and Meta-Analysis. American Journal of Obstetrics and Gynecology, 221, 194-207.E5. https://doi.org/10.1016/j.ajog.2019.02.022

[9] Brenchtl, J.R., Breibart, W., Galietta, M., Krivo, S. and Rosenfeld, B. (2001) The Use of Highly Active Antiretroviral Therapy (HAART) in Patients with Advanced HIV Infection-Impact on Medical, Palliative Care and Quality of Life Outcome. Journal of Pain and Symptom Management, 21, 41-51. https://doi.org/10.1016/S0885-3924(00)00245-1

[10] Deeks, S.G. (2011) HIV Infection, Inflammation, Immunosenescence, and Aging. Annual Review of Medicine, 62, 141-145.

https://doi.org/10.1146/annurev-med-042909-093756 
[11] Chiu, C.G., Smith, D., Salters, K.A., Zhang, W., Kanters, S., Milan, D., Montaner, J.S.G., Coldman, A., Hogg, R.S. and Wiseman, S.M. (2017) Overview of Cancer Incidence and Mortality among People Living with HIV/AIDS in British Columbia, Canada: Implications for HAART Use and NADM Development. BMC Cancer, 17, Article No. 270. https://doi.org/10.1186/s12885-017-3229-1

[12] Maartens, G., Celum, C. and Lewin, S.R. (2014) HIV Infection, Epidemiology, Pathogenesis, Treatment and Prevention. The Lancet, 384, 258-271.

https://doi.org/10.1016/S0140-6736(14)60164-1

[13] Sigel, K., Dubrow, R., Silverberg, M., Crothers, K., Braithwaite, S. and Justice A. (2011) Cancer Screening in Patients Infected with HIV. Current HIVIAIDS Reports, 8, 142-152. https://doi.org/10.1007/s11904-011-0085-5

[14] Kharsany, A.B.M. and Karim, Q.A. (2016) HIV Infection and AIDS in Sub-Saharan Africa: Current Status, Challenges and Opportunities. The Open AIDS Journal, 10, 34-48. https://doi.org/10.2174/1874613601610010034

[15] Bashorun, A., Nguku, P., Kawu, I., Ngige, E., Ogundiran, A., Sabitu, K., Nasidi, A. and Nsubuga, P. (2014) A Description of HIV Prevalence Trends in Nigeria from 2001 to 2010: What Is the Progress, Where Is the Problem? Pan African Medical Journal, 18, Article No. 3. https://doi.org/10.11604/pamj.supp.2014.18.1.4608

[16] Ibrahim, S.A., Sabihi, K., Abubakar, A., Poggensee, G., Ibrahim, S., Riyad, M., Bashorun, A., Sudawa, A.U., Ibrahim, S.B., Mohammed, H., Ezeudu, C., Abubakar, A.A., Nsubuga, P. and Nguku, P. (2019) Demographic Factors Associated with HIV Infection between Low and High Prevalence Areas in Nigeria: 2015. Pan African Medical Journal, 32, Article No. 11. https://doi.org/10.11604/pamj.supp.2019.32.1.13330

[17] National Agency for the Control of AIDS (NACA) (2019). https://naca.gov.ng

[18] Ugwu, E.O.V., Iferikigwe, S.E., Okeke, T.C., Ugwu, A.O., Okezie, O.A. and Agu, P.U. (2011) Pattern of Gynaecological Cancers in University of Nigeria Teaching Hospital, Enugu, South Eastern Nigeria. Nigerian Journal of Medicine, 20, 266-269.

[19] Umeobika, J.C., Ikeako, L.C., Ezenyeaku, C.T., Ezebialu, U.I. and Ojiyi, E.C. (2018) Gynaecological Malignant Tumours at Imo State University Teaching Hospital Orlu South Eastern Nigeria. Afrimedic Journal, 6, 52-58.

[20] Agboeze, J., Ezeonu, P.O., Onoh, R.C., Nwali, M.I., Agwu, M. and Egbuji, C.C (2015) Frequency and Pattern of Gynecological Cancers in Federal Teaching Hospital, Abakaliki, Nigeria. Journal of Basic and Clinical Reproductive Sciences, 4, 54-57.

[21] Ogunlaja, O.A., Akinola, S.E., Bakare, Y.T., Adeniran, A.S., Ogunlaja, I.P., Olasinde, A., Adetoye, F., Bowale, D., Kasali, O., Oladeji, I., Oyedele, T.J. and Salawu, B.T. (2022) An Appraisal of Pattern and Presentation of Gynaecological Malignancies in Bowen University Teaching Hospital, Southwest Nigeria. Research Journal of Health Sciences, 10, 1-8. https://doi.org/10.4314/rejhs.v10i1.1

[22] Traore B., Bah, T.S., Traore, F.A., Sow, M.S., Diane, S., Keita, M., Cisse, M., Koulibaly, M. and Camara, N.D. (2015) The Prevalence of HIV in Cancer Patients at the Surgical Oncology Unit of Donka University nHospital of Conakry (Guinea). Journal of Cancer Epidemiology, 2015, Article ID: 387896, 4 p. https://doi.org/10.1155/2015/387896

[23] Adewuyi, S.A., Oguntayo, A.O., Samaila, M.O.A. and Adewuyi, K.R. (2018) Age Distribution, Site of Origin and HIV Status of Cases of Gynaecological Malignancies Seen at a Radiotherapy Facility in Northern Nigeria. Archives of International Surgery, 5, 11-15. https://doi.org/10.4103/2278-9596.153147 
[24] Moodley, M. and Mould, S. (2005) Invasive Cervical Cancer and Human Immunodeficiency Virus (HIV) Infection in KwaZulu-Natal, South Africa. Journal of $O b$ stetrics and Gynaecology, 25, 706-710. https://doi.org/10.1080/01443610500294599

[25] Centers for Disease Control and Prevention (2019) Gynecologic Cancer Incidence, United States-2012-2016. USCS Data Brief, No. 11, Centers for Disease Control and Prevention, US Department of Health and Human Services, Atlanta.

[26] Moodley, M., Moodley, J. and Kleinschmidt, I. (2001) Invasive Cervical Cancer and Human Immunodeficiency Virus (HIV) Infection: A South African Perspective. International Journal of Gynecological Cancer, 11, 194-197.

[27] Bohlius, J., Foster, C., Naidu, G., Sengayi, M. and Turkova, A. (2018) Cancer in Adolescents and Young Adults Living with HIV. Current Opinion in HIV and AIDS, 13, 196-203. https://doi.org/10.1097/COH.0000000000000460

[28] Basazinewu, Z.D. (2018) An Assessment Study on the Prevalence and Causes of Early Marriage and Its Associated Problems in Socio-Economic and Health of Women in Gozamine Wareda East Gojjame ZoneAmhara Region. International Journal of Social Sciences Perspectives, 2, 1-37. https://doi.org/10.33094/7.2017.2018.21.1.37

[29] Ononogbu, U., Almujitaba, M., Modibbo, F., Lawal, I., Offiong, R., Olaniyan, O., Dakum, P., Spiegelman, D., Blattner, W. and Adebamowo, C. (2013) Cervical Cancer Risk among HIV Infected Nigerian Women. BMC Pub Health, 13, Article No. 582. https://doi.org/10.1186/1471-2458-13-582

[30] Nkeyekyer, K. (2000) Pattern of Gynaecological Cancer in Ghana. East African Medical Journal, 77, 534-538.

[31] Levinson, K.L., Riedel, D.J., Ojalvo, L.S., Chan, W., Angarita, A.M., Fader, A.N. and Rositch, A.F. (2018) Gynecologic Cancer in HIV-Infected Women: Treatment and Outcomes in a Multi-Institutional Cohort. AIDS, 32, 171-177. https://doi.org/10.1097/QAD.0000000000001664

[32] Torre, L.A., Bray, F., Siegel, R.L., Ferlay, J., Lortet-Tieulent, J. and Jemal A. (2015) Global Cancer Statistics, 2012. CA: A Cancer Journal for Clinicians, 65, 87-108. https://doi.org/10.3322/caac.21262

[33] El-Sadr, W.M., Rabkin, M. and DeCock, K.M. (2016) Population Health or Individualized Care in Global AIDS Response: Synergy or Conflict? AIDS, 30, 2145-2148. https://doi.org/10.1097/QAD.0000000000001192

[34] Rose, P.G. and Cheeseman, S.H. (1993) Advanced Ovarian Carcinoma Managed in an HIV-Positive Patient. Gynecologic Oncology, 48, 132-134.

https://doi.org/10.1006/gyno.1993.1022

[35] Sekowski, A., Ooko, F.O., Napo, H. and Mphahlele, R.J. (2008) HIV-Related Cancer of the Vulva in Young Women: A Clinicopathologic Study of 5 Cases. Journal of Obstetrics and Gynaecology, 28, 555-557. https://doi.org/10.1080/01443610802246917

[36] Brown, J.E., Sunborg, M.J., Kost, E., Cosin, J.E.A. and Winter, W.E. (2005) Vulvar Cancer in Human Immunodeficiency Virus-Seropositive Premenopausal Women: A Case Series and Review of Literature. Journal of Lower Genital Tract Disease, 9, 7-10. https://doi.org/10.1097/00128360-200501000-00003

[37] Wilailak S., Kengsakul, M. and Kehoe, S. (2021) Worldwide Initiatives to Eliminate cervical Cancer. International Journal of Gynecology \& Obstetrics, 155, 102-106. https://doi.org/10.1002/ijgo.13879

[38] Okunowo, A.A., Alakaloko, M.A., Ohazurike, E.O., Okunade, K.S. and Anorlu, R.I. (2019) Trend and Characteristics of Endometrial Cancer in Lagos, Nigeria. Gulf Journal of Oncology, 31, 51-59. 
[39] Koneru, A., Jolly, P.E., Blakemore, S., McCree, R., Lisovicz, N.F., Aris, E.A., Mtesigwa, T., Yuma, S. and Mwaiselage, J.D. (2017) Acceptance of Peer Navigators to Reduce Barriers to Cervical Cancer Screening and Treatment among Women with HIV Infection in Tanzania. International Journal of Gynecology \& Obstetrics, 138, 53-61. https://doi.org/10.1002/ijgo.12174

[40] Adibe, M.O. and Aluh, D.O. (2018) Awareness, Knowledge, and Attitudes towards Cervical Cancer amongst HIV-Positive Women Receiving Care in a Tertiary Hospital in Nigeria. Journal of Cancer Education, 33, 1189-1194.

https://doi.org/10.1007/s13187-017-1229-0

[41] Batra, P., Kuhn, L. and Denny, L. (2010) Utilization and Outcomes of Cervical Cancer Prevention Services among HIV-Infected Women in Cape Town. South African Medical Journal, 100, 39-44.

[42] Catarino, R., Petignat, P., Dongui, G. and Vassilakos, P. (2015) Cervical Cancer Screening in Developing Countries at a Crossroad: Emerging Technologies and Policy Choices. World Journal of Clinical Oncology, 6, 281-290. https://doi.org/10.5306/wjco.v6.i6.281

[43] Xie, Y., Tan, X., Shao, H., Liu, Q., Tou, J., Zhang, Y., Luo, Q. and Xiang, Q. (2017) VIA/VILI Is More Suitable for Cervical Cancer Prevention in Chinese Poverty-Stricken Region: A Health Economic Evaluation. BMC Public Health, 17, Article No. 118. https://doi.org/10.1186/s12889-017-4054-9

[44] Anorlu, R.I., Obodo, K. and Makwe, C.C. (2009) Cancer Mortality among Patients Admitted to Gynecological Wards at Lagos University Teaching Hospital, Nigeria. International Journal of Gynecology \& Obstetrics, 110, 268-269. https://doi.org/10.1016/j.ijgo.2010.03.038

[45] Leonard Ogbonna Ajah, L.O., Ifezuoke, D.T., Ajah, M.I., Nwankwo, T.O., Ezeome, I.V., Umeh, U.A. and Agu, P.U. (2021) Complementary and Alternative Medicine Use among Gynaecological Cancer Patients in Enugu, South-East Nigeria. Global Journal of Health Science, 13, 16-23. https://doi.org/10.5539/gihs.v13n9p16

[46] Tapera, O., Dreyer, G., Kadzatsa, W., Nyakabau, A.M., Pedersen-Stray, B. and Hendricks, S.J.H. (2019) Cervical Cancer Knowledge, Attitudes, Beliefs and Practices of Women Aged at Least 25 Years in Harare, Zimbabwe. BMC Women's Health, 19, Article No. 91. https://doi.org/10.1186/s12905-019-0790-6

[47] Maiman, M., Fruchter, R.G., Serur, E. and Remy, J.C. (1990) Human Immunodeficiency Virus and Cervical Neoplasia. Gynecologic Oncology, 38, 377-382.

https://doi.org/10.1016/0090-8258(90)90077-X

[48] Ananworanich, J., Dube, K. and Chomont, N. (2015) How Does the Timing of Antiretroviral Therapy Initiation in Acute Infection Affect HIV Reservoirs? Current Opinion in HIV and AIDS, 10, 18-28.

https://doi.org/10.1097/COH.0000000000000122

[49] Suneja, G., Boyer, M., Yehia, B.R., Shiels, M.S., Engels, E.A., Bekelman, J.E. and Long J.A. (2015) Cancer Treatment in Patients with HIV Infection and Non-AIDSDefining Cancers: A Survey of US Oncologists. Journal of Oncology Practice, 11, e380-e387. https://doi.org/10.1200/JOP.2014.002709

[50] Suneja, G. (2018) New NCCN Guidelines: Cancer Management in People Living with HIV. Journal of the National Comprehensive Cancer Network, 16, 597-599. https://doi.org/10.6004/jnccn.2018.0033

[51] National Cancer Institute (n.d.) HIV Infection and Cancer Risk. https://www.cancer.gov/about-cancer/causes-prevention/risk/infectious-agents/hivfact-sheet 